\title{
Global View of a Sustainable Society and Its Stability
}

\section{Helmut Burkhardt}

Ryerson University

digital.library.ryerson.ca/object/232

Please Cite:

Burkhardt, H. (1991). Global view of a sustainable society and its stability.

Proceedings of the 1991 International Symposium on Technology and Society ISTAS '91, 73-79.

doi:10.1109/ISTAS.1991.700351

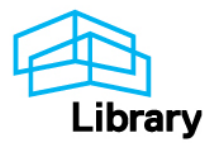




\title{
GLOBAL VIEW OF A SUSTAINABLE SOCIETY AND ITS STABILITY
}

\author{
Helmut Burkhardt \\ Ryerson Polytechnical Institute \\ Toronto, Ontario, Canada \\ M5B 2K3 \\ Paper Presented at the Interdisciplinary Conference: \\ PREPARING FOR A SUSTAINABLE SOCIETY \\ Toronto, June 21/22, 1991
}

\begin{abstract}
It is often said, and at present it is probably true that famine and poverty in some parts of the world are a problem of distribution rather than one of production of the necessities of life. The improvement of our distribution system, however, does not only solve an acute problem of regional deprivation, but also creates regional interdependence. Thus, with present day transcontinental trade the questions related to sustainability become global issues. The whole world is an interconnected network. Is there some "invisible hand" which guides local actions in a direction beneficial to the whole or does this connectedness necessitate deliberate global planning?

A similar question arises when we look far ahead in time. Many people have a blind trust in the future and are unconcerned with questions of long term sustainability of human civilization. Those who believe in science and technology respond to warnings of global sustenance problems: "The engineers will invent something that will solve our problems." Those with a religious bent say: "Why worry about tomorrow? 'He' who has provided for us in the past will do so in the future." How useful is this fatalistic stance today? Given the knowledge we possess, are we not responsible for irreversible damages to the Planet which will burden future generations? Is mankind capable of consciously choosing its future path?

This paper analyses the state of the World and the stability of the processes in it. We take a global and long term perspective. The basic tool used is a balance equation for material, cultural, biological, social and ecological substances. Conditions for sustainable, dynamic equilibria are derived and presented in per capita values in order to facilitate intuitive comprehension. Possible contributions to sustainability of the natural sciences and engineering and of the social sciences and the humanities are outlined. In conclusion some desirable and some accidental paths to sustainability are given.
\end{abstract}

\section{Introduction}

The sustenance of human civilization in the long term is a formidable task. The sustainable society we are aiming for is a big system of some 5 billion or more individuals distributed over the entire Globe. Is there, as in Adam Smith's free market economy, an "invisible hand" which guides us towards the good of the whole tomorrow while we pursue our well-being locally today?

In the past there was no coherent global system. The populated regions then were autonomous and self-sufficient within their geographic boundaries, and there were undeveloped areas between them. It was possible to emigrate when one's own locality got overcrowded. At the present time, 


\section{GLOBAL VIEW...}

however, there are few virgin lands left, the livable regions have become contiguous, and further local growth creates higher pressure around the Globe. In this situation our mobile population behaves like a fluid with the Globe as the container. Local pressure is transmitted to the entire 'container'. It is this condition which necessitates a global analysis for an understanding of local issues.

\section{Substance Accounting for the Earth and Conditions for Stable Steady States}

\section{Aristotelian Substance}

The concept of a substance as we use it today is narrow, almost synonymous with chemical substance. Aristotle's definition of a substance is wider. Before using this expanded notion of substance it is appropriate to discuss it.

A substance in the sense of Aristotle is anything which exists. A primary substance is a concrete individual unit of substance which consists of a certain amount of mass-energy, the substratum, and a characteristic space-time structure of that substratum. A secondary substance in Aristotle's definition is a class of primary substances which are characterized by certain features of the individuals belonging to the class [1].

It is interesting to note one common property amidst the great diversity of substances. All substances appear to have, at least conceptually, an atomistic or holistic nature. The basic unit of a primary substance cannot be divided without destroying its essential features. Several examples may illustrate this point. Half of a circle is not a circle. Parts of a divided word are either words with a changed meaning or meaningless syllables. When we divide water, each part is still water, but, if we divide the smallest unit of water, the primary substance, the individual water molecule, then we get oxygen and hydrogen. The same is true for life organisms. Half of a cat certainly does not display the characteristic space-time behaviour of a whole cat. The question arises: do large, complex systems have this 'atomistic' structure too? How far can we reduce ecosystems before they lose their essential features? Is half a rain forest still a rain forest, or does it turn into something qualitatively different?

\section{The Earth as an Accounting Entity}

If we put a Gauss surface, an imagined, topologically closed surface around the Earth then we have it clearly separated from the rest of the universe. This 'Gauss container' is a well defined accounting entity [2]. The state of the Earth can now be described by a list of contents of amounts of substances ' $\mathrm{X}$ ', which we call an inventory 'I' of the imagined 'Gauss bubble'.

Due to the large amounts of substances in the global list of resources it is preferable to list the per capita values, or in some cases the local densities or concentrations of the substances considered.

The change of state DI is described as a list of changes of amounts of substance DX

$$
\mathrm{DI}=[\mathrm{DX} 1, \mathrm{DX} 2, \mathrm{DX} 3, \ldots . .] \text {. }
$$

Any changes occurring in a Gauss container can be ascribed to two logically possible processes: internal production of substances PX, or to transfers of substances through the Gaussian surface TX. All changes DX can thus be predicted by observing all productions inside and all transfers through the Gauss surface. See Fig. 1. 


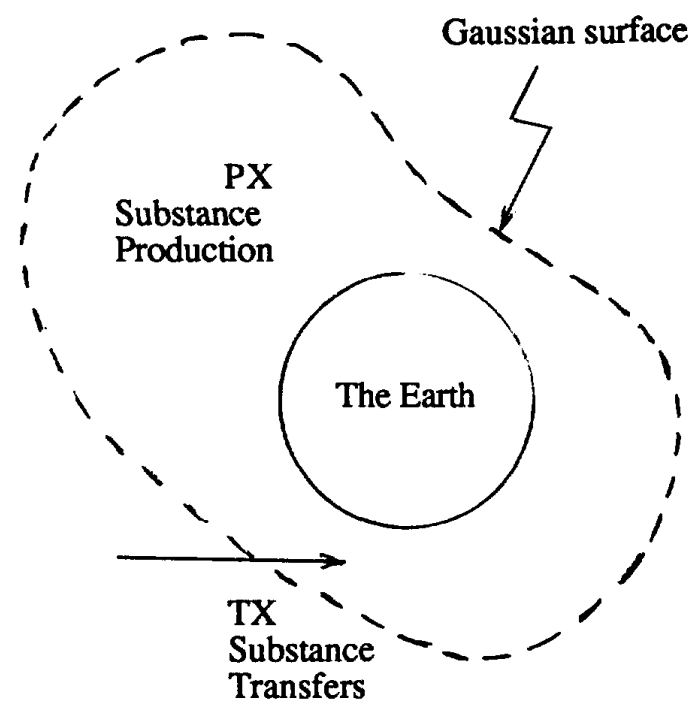

Fig. 1

The Earth in a 'Gauss Container'. The interior of the Gaussian surface defines our accounting entity.

The substance inventory can only change by transfer or by production.

The change DX of the amount of a substance is related to the processes of transfer and production by a basic balance equation:

$$
\mathrm{DX}=\mathrm{TX}+\mathrm{PX}
$$

The steady state of a system is marked by no change in the inventory which means all DX $=0$, or $\mathrm{DI}=0$. This no change situation is by no means static or motionless. $\mathrm{DI}=0$ is the result of ongoing processes of transfers and production which compensate each other. This state is often referred to as a dynamic equilibrium state. Ludwig von Bertalanffy [3], a pioneer of systems science, called the dynamic equilibrium state a "flow equilibrium" ( Fliessgleichgewicht ). Systems in such states are "open" systems.

\section{Feedback. Stability and Sustainability}

Process rates usually depend on the inventory. Negative feedback occurs when a positive change in the inventory causes a negative change in production or transfer. This leads to a stable world, a sustainable state. For example, an increased solar activity brings more solar heat to the Earth and makes it warmer. The consequence of that is an increased infrared radiation from the Earth into space. There results a new energy flow equilibrium at a slightly higher temperature. Barring other effects, the Earth's climate is in a sustainable state as a result of a stable energy flow equilibrium with negative feedback.

When an inventory increase leads to a positive change in production or transfer then that positive feedback causes explosive, runaway changes or instabilities. Unstable equilibrium states are difficult to sustain. For example, consider again an increased solar radiation. The resulting increase in the Earth's temperature makes the polar ice caps smaller causing more solar radiation to be absorbed. Or, in the other direction, a reduction of solar radiation causes cooling and further reduction of solar heat by increased reflection from the growing polar ice caps. Thus, the Earth's climate changes are enhanced by positive feedback, and the climate tumbles between ice ages and hot periods following minor disturbances in solar radiation capture as for example through 


\section{GLOBAL VIEW...}

increased carbon dioxide in the atmosphere. The correlation between solar input and ice formation on the polar caps causes the Earth's climate to be in an unstable flow equilibrium. Fortunately the flip-flop frequency is small, and the amplitude is not so large as to interrupt life on Earth completely.

\section{Sustenance Issues Arising from Man-Made Changes}

The sustainability of some vital substances may be threatened by natural or man induced processes. F. Vester illustrates by examples in his book on the world as an interconnected network system that in most cases the threat to one substance comes from another one [4]. Therefore, the issues raised by sustainability discussion are likely to be transdisciplinary. Engineering tasks are generally motivated by biological or social desires or limitations, and are coupled with economy and with the political will. Most problems of sustainability are primarily in the social, political and ecological domains. Engineering and science play a supportive role in the quest for sustainability.

The following substances are considered with regard to their impact on a sustainable society: human life, other life forms, land, energy, material resources, pollutants, radioactive isotopes, oxygen, ozone, and carbon dioxide. The data used in this presentation were extracted from 'Our Common Future' [5], 'The State of the World' [6], 'Planet Under Stress' [7], 'Energy in a Finite World' [8], 'The Population Explosion'[9], and 'Physics and the Nuclear Arms Race'[10].

\section{Quality and Quantity of Life}

Naturally, for human beings, human life is the key to all sustainability discussion. The quality and the quantity of human life on Earth are the very reasons for all our activities.

The quality of life correlates with the life expectancy. It has, on average, steadily increased with the medical and technical services that mankind has been able to find in the last several generations. It is one of the major concerns to expand the privilege of medicare and guaranteed food supply to the developing regions of the Globe.

The quantity of human life on Earth is probably the most crucial parameter in all sustainability discussions. The human world population has shown explosive growth in the recent past. At the present rate it is almost doubling in one generation. The population change is driven by several positive feedbacks. The increase in population causes an increase in the reproduction rate. Improving medicare and food production is reducing the death rate. The negative feedback mechanisms, such as as reduced birth rates due to improved quality of life, are too small to be relevant. The predictions are that the world population will double in a little more than one generation.

There is evidence that the growth of the World population has to stop now if we are to achieve a sustainable state of our civilization by design [5]. The alternative is that nature (the "Lord") provides us with a solution, and that is likely to be a very painful and deadly experience for most of us.

What can scientists and engineers do to solve problems caused by population growth? Our experience with fighting poverty in developing countries, and with reducing the consumption in developed regions during the oil crisis in the 70's has shown that we are fighting a losing battle. Scientists and engineers do struggle to gain a few percentage points in the efficiency of a technology in one generation. It appears to be impossible to double the standard of living in poor countries and to halve the consumption in the wealthy countries during one population doubling 


\section{GLOBAL VIEW...}

period. No science and technology can achieve that at any level of funding, let alone at one or two percent of the GNP level at which scientific research and development are presently operating.

Animal and plant life, apart from human life, is the next precious substance on Earth. While we value artifacts such as a Van Gogh painting for its uniqueness and beauty, each species of life is a unique time space structure many times more intricate than a piece of human art and it should be valued accordingly. Some scientists argue that we should value the other species of life for practical reasons. The existence of a great variety of genetic material does help humans to survive. A large variety of natural genetic material is useful in biotechnology for the improvement of medicine and food production. Even with the advent of genetic engineering we cannot replace the great diversity of natural genetic material, particularly that of the higher forms of life. The world's inventory of life species is a long list of several million items. The natural loss rate before man's interference was some 2 species per year. At present we are losing an alarming several thousand species per year [5]. Man, for selfish reasons, should grant ample unencumbered living space to other life forms.

Land

Land is the most critical of all our resources. At the present world population level we have some 10 ha of the Globe's surface to each living human being; that includes 7 ha of ocean per person; the land surface per person is 3 ha; this includes 2 ha per person of hot or cold deserts. We have about 1 ha of green land per person; this is approximately the size of a soccer field and that includes the ranch land; one cow requires about that much of pasture to survive on. We have 0.33 ha of fertile land per person, and that includes the rain forests. We have about $0.16 \mathrm{ha}$ of agricultural land per person on the Globe, and yet we need .2 ha of fertile land to feed a person by sustainable, organic farming. Therefore, the reason for cutting down the rain forests is not just the greed of some individuals. On a global scale, there is a genuine need for more agricultural land.

\section{Energy}

Energy, contrary to a wide spread opinion, is plentiful, and a flow equilibrium of energy is possible in the long run. Scientists and engineers can develop a sustainable solar energy technology providing ample energy for every one at any forseeable level of world population. The sun supplies some $13 \mathrm{PW}$ to the globe which is, at present world population, $24.000 \mathrm{~kW}$ per person. By comparison, the total power used by people living a European life style is $5 \mathrm{~kW}$ per person. Using biomass for generating $5 \mathrm{kw}$ per person requires some $.2 \mathrm{ha}$ of fertile land per person which is obviously in conflict with land availability. The direct use of solar energy requires less than 0.01 ha per person, i.e. some $100 \mathrm{~m}^{\wedge} 2$ and not necessarily green land. Therefore, direct use of solar energy is more efficient and has great potential for a sustainable future.

Fossil fuels are being used up without replacement, and a flow equilibrium for fossil fuels cannot exist in principle, and therefore, they cannot make a sustainable energy system. King Hubbard predicted in the 1950's that cheap oil supplies would run out in the 1970's. Indeed, in a historic, long-term perspective the contribution of oil is minimal, and the curve of oil use vs. historic time is often described as the "Hubbard pimple". Coal lasts a bit longer, but apart from its pollution problem it is not sustainable either. Besides, the carbon dioxide from fossil fuel use, it is feared, will cause a change in our climate.

Nuclear fuels, particularly for fusion or breeder reactors, are abundant and might well serve as a long-term energy source if it was not for the production of radioactive materials. The radioactive 


\section{GLOBAL VIEW...}

byproducts of nuclear power generation accumulate on Earth, and represent a threat to our environment. The radioactive decay process, in a subcritical concentration of the materials, has a negative feedback: an increase in the level of radioactive substances also increases the decay rate, and the process is intrinsically stable. A nuclear power system has, however, many other flaws: it weakens the defense of a nation since it is vulnerable to attack. Luckily, Kuwait did not have any nuclear reactors during the recent Gulf war. Nuclear reactors also contribute to the proliferation of nuclear weapons [10].

\section{Materials}

Material resources other than energy can be recycled or substituted by other materials, and therefore do not represent a fundamental problem for a sustainable society. The same is true for pollutants accumulating in our environment. As long as there is a political will to manage the environment, and a supply of energy to act accordingly, unwanted chemicals can be atomized and recycled.

Oxygen in our atmosphere, due to the inorganic chemical equilibrium alone, is $2 \%$ [11]. Without the oxygen contribution of the biosphere we would suffocate in the Earth's atmosphere. Of the total biological oxygen production the rain forests contribute some $30 \%$. A very good reason, apart from many others, to save the rain forests.

Carbon dioxide in the Earth's atmosphere is coupled with oxygen. Disintegrating biomass generates carbon dioxide and depletes oxygen in our atmosphere. While there is a heated discussion on the carbon dioxide question, it is, by itself, a stable dynamic equilibrium. Increased carbon dioxide causes a warmer climate through the greenhouse effect. In turn, higher temperature causes ice to melt and that leads to more humidity in the air. All these effects enhance the growth rate of plants which reduces carbon dioxide in the atmosphere by binding it to the plant material. This multiple negative feedback strongly indicates stability of the dynamic equilibrium of carbon dioxide levels in our atmosphere.

Ozone in our atmosphere is another chemical substance relevant to human well-being in the future. However, there is no catastrophe potential in the ozone depletion problem. We have to suffer the damage we are doing, correct our wrongs, and wait for the ozone layer to recover in one or two generations. There is no positive feedback in the ozone cycle and, therefore, no runaway effects are to be expected in the ozone problem.

\section{Artifacts}

All artifacts of civilization are gradually decaying and will eventually be lost. Historic buildings, human settlements and transportation networks will eventually be lost through the natural impact of the weather or through war. In spite of man's effort to preserve cultural artifacts in museums, all tools, machinery, books and works of art are subject to gradual decay and to destruction by fires, e.g. the ancient library in Alexandria.

'Mental artifacts', religions, cultures and ideologies come and go as do the physical artifacts. Excluding a global nuclear war, the time constant for the loss of artifacts is long and, therefore, there is no threat to a sustainable society from the loss of artifacts. Our 'social memory' appears to be long enough to allow for new artifacts to develop before the old ones are forgotten. Besides, they can be reinvented if forgotten, and rebuilt if lost. We even destroy old artifacts willfully in order to make room for new ones. Artifacts like robots or computers cannot (yet) self-reproduce; it is unlikely that they will threaten the sustainability of human society by "taking over". 


\section{GLOBAL VIEW...}

\section{Conclusion}

World population is the central variable in the sustainability equation. It has a positive feedback and therefore it has the potential for runaway changes. We should all strive to control the quantity and quality of human life by design rather than by accident.

Agricultural land for sustainable food production is already in short supply at the present level of world population. Land is the critical resource for a sustainable society. There is little flexibility in the supply of agricultural land.

Living space for the many biological species is scarce already. On average, nations set some $5 \%$ of their land aside for wilderness areas, and even that small amount is already under pressure to be used for human purposes. World parks financed by World taxes are urgently needed. Deep ecology has an important message: we must grant adequate living space to all life forms. Animal rights are demanded by human self interest.

Feasible long term solutions for the energy problem are seen in the direct use of solar energy. Scarcity of material resources and problems of environmental degradation are seen as solvable by recycling used materials and by substituting new materials for conventional ones.

Science and engineering can make only marginal contributions to a sustainable society. The real task in achieving a sustainable society is the development of a collective will to control the world population, and that is a matter for the religious, social and political domains.

[1] Aristotle, in R. McKeon, The Basic Works of Aristotle, Random House, N.Y., 1941, p. 8 \& 9

[2] Burkhardt, H. Substance Accounting: A Fundamental Knowledge Structure for All Disciplines. In Proc. of Annual Conference of the American Society for Engineering Education. Toronto, June 1990, p. 1762

[3] Bertalanffy, L.v., W. Beier and R. Laue, Biophysik des Fliessgleichgewichts, Vieweg, Brauuschweig, 1977.

[4] Vester, F., Unsere Welt, ein vernetztes System, Klett-Cotta, Stuttgart, 1978.

[5] Brundtland, G.H., Our Common Future, Oxford University Press, N.Y., 1987.

[6] Brown, L. et.al., State of the World, 1990, Norton, New York, 1990.

[7] Mungall, C. and D.J. McLaren, Planet Under Stress, Oxford University Press, N.Y., 1990.

[8] Haefele, W., Energy in a Finite World, Ballinger, Cambridge, Mass., 1981.

[9] Ehrlich, Paul R., and Anne H. Ehrlich, The Population Explosion, Simon and Schuster, N.Y., 1990.

[10] Schroer, D., and J. Dowling, Physics and the Nuclear Arms Race, Am. Assoc. of Physics Teachers, Maryland, 1984.

[11] F. Herrmann, University of Karlsruhe, private communication. 